\title{
Analgesic Effect of Dexmedetomidine or Magnesium Sulphate Added to Bupivacaine in Interscalene Brachial Plexus Block During Shoulder Arthroscopy
}

DOAA A. ELZEFTAWY, M.Sc.; MOHAMAD A. EL-HARTY, M.D.; AHMED S. ELGEBALY, M.D. and MONA B. FAYAD, M.D.

The Department of Anesthesiology and Surgical Intensive Care, Faculty of Medicine, Tanta University

\begin{abstract}
Background: Shoulder surgery is accompanied with significant post-operative pain. Interscalene block is one of regional techniques which is effective and safe to control this pain. Magnesium Sulphate (MgSO 4) \& dexmedetomidine as adjuvants to bupivacaine is expected to prolong the block with minimal undesirable systemic effects.
\end{abstract}

Aim of Study: The aim of this work was to evaluate the post-operative analgesic effects of ultrasound guided interscalene brachial plexus block in elective shoulder surgeries under general anesthesia using either bupivacaine, bupivacainemagnesium sulphate or bupivacaine-dexmedetomidine.

Material and Methods: This double blind RCT was carried out on 45 patients of both sexes, 18-60y, ASA I or II and scheduled for elective arthroscopic shoulder surgeries under GA. US guided interscalene block with total volume $20 \mathrm{ml}$ was done to all patients who randomly allocated into 3 equal groups: Group I (control group): $0.25 \%$ bupivacaine $18 \mathrm{ml}$, Group II (Mg group): $0.25 \%$ bupivacaine $18 \mathrm{ml}+2 \mathrm{ml} 10 \%$ MgSO4 200mg and Group III (Dex group): $0.25 \%$ bupivacaine $18 \mathrm{ml}+2 \mathrm{ml}$ dexmedetomidine (100 g) HR \& MAP at baseline, skin incision, 30, 60, $90 \& 120 \mathrm{~min}$ after skin incision and at $2 \mathrm{~h}, 4 \mathrm{~h}, 6 \mathrm{~h} \& 8 \mathrm{~h}$ post-operative, onset $\&$ duration of sensory block, (VAS \& sedation score) at 2, 4, 6, 8 \& $12 \mathrm{hrs}$ postoperative, onset of 1 st and total dose of meperidine and complications were measured.

Results: Our results showed no significant difference as regard to age, sex, ASA, duration \& type of surgery, sedation score but there was significant decrease in HR, MAP, VAS onset of sensory block \& 1 st analgesic requirements, total dose of rescue analgesic and prolongation in sensory block in $\mathrm{Mg}$ group \& Dex group as compared to control group \& also Dex group was superior to $\mathrm{Mg}$ group.

Conclusion: Dexmedetomidine $100 \mu \mathrm{g}$ was better than $\mathrm{MgSO}_{4} 200 \mathrm{mg}$ when they added to bupivacaine $0.25 \%$ in US guided interscalene brachial plexus block as evidenced by prolongation of sensory block, improved quality of postoperative analgesia, decreased requirements of rescue analgesics and providing desirable sedation without side effects.

Correspondence to: Dr. Doaa A. El-Zeftawy, The Department of Anesthesiology and Surgical Intensive Care, Faculty of Medicine, Tanta University
Key Words: Dexmedetomidine - Magnesium sulphate - Interscalene brachial plexus block - Shoulder arthroscopy.

\section{Introduction}

SHOULDER surgery is accompanied with significant post-operative pain [1]. Multimodal pain control is associated with less opioid requirements and its complications e.g. respiratory depression, post-operative nausea and vomiting, pruritus and constipation [2].

Interscalene nerve block is one of regional techniques which is effective and safe to control pain. Ultrasound (US) guidance is increased in popularity as it leads to precise needle placement can show the anatomical variations, decreases pain associated with the maneuver.

Bupivacaine is the commonest local anesthetic used with duration of 3-6hr [3]. Magnesium sulphate $(\mathrm{MgSO} 4)$ \& dexmedetomidine as adjuvants to bupivacaine is expected to increase the duration of block without minimal undesirable systemic effect [4].

The aim of this work was to evaluate the postoperative analgesic effects of US guided interscalene brachial plexus block in elective shoulder surgeries under general anesthesia using either bupivacaine, bupivacaine-magnesium sulphate or bupivacaine-dexmedetomidine.

\section{Material and Methods}

This prospective double blinded randomized controlled trial was carried out at Tanta University Hospitals for one year from March 2017 to March 2018. After approval from the Institutional Ethical 
Committee and a written informed consent was obtained from the participants. 45 patients of both sexes aged $18-60 y$, ASA physical status I or II and scheduled for elective arthroscopic shoulder surgeries under General Anesthesia (GA) were enrolled. Every patient received an explanation to the purpose of the study \& detailed explanation for the technique used. Every patient had a secret code number \& photos applied only to the part of the body linked to the research to insure privacy to the participants \& confidentiality of data.

Exclusion criteria were: Refusal of the patient, coagulopathy \& bleeding disorders, neurological deficits of upper limbs, pregnant \& lactating females, drug abuse \& chronic analgesic use, chronic treatment with calcium channel blockers, hypermagnesemia, history of allergy to local anesthetic drugs or any of the study drugs, inability to understand Visual Analogue Score (VAS) for pain assessment and respiratory disease as chronic obstructive pulmonary diseases \& unstable asthma.

US guided interscalene block ( $20 \mathrm{ml}$ volume) was done to all patients \& according to the drug injected, patients were randomly allocated into 3 groups each of 15 patients: Group I: Bupivacaine group (control group): $0.25 \%$ bupivacaine $18 \mathrm{ml}+$ normal saline $2 \mathrm{ml}$, Group II: Magnesium sulphate group (Mg group): $0.25 \%$ bupivacaine $18 \mathrm{ml}+10 \%$ MgSO 4 2ml (200mg) and Group III: Dexmedetomidine group (Dex group): $0.25 \%$ bupivacaine $18 \mathrm{ml}+$ dexmedetomidine $2 \mathrm{ml}(1 \mathrm{ml}$ dexmedetomidine 100 microgram plus $1 \mathrm{ml}$ normal saline).

Randomization was performed using computer generated random numbers concealed in sealed envelopes indicating the group of assignment, a blinded nurse who didn't participate in the study or data collection, read the number contained in the envelope and made group assignment.

All patients were subjected to a careful history taking, complete physical examination and routine laboratory investigations were done. Patients fasted for 6 hours for solids, 4 hours for semisolids \& 2 hours for clear fluids. VAS was explained to the patients \& all patients were well trained to use it.

On arrival to OR, an IV line was established with $18 \mathrm{G}$ cannula in all patients in the non-operative side, standard monitoring was applied including ECG, pulse oximetry \& noninvasive arterial blood pressure, all patients received midazolam $2 \mathrm{mg}$ IV before the procedure. Local anesthetic mixtures were prepared in the OR by an anesthesia resident who wasn't involved in either performing the block or collecting the data. Each mixture was reserved in $20 \mathrm{ml}$ syringe, kept on a sterile table and covered.

\section{Technique of US guided interscalene block:}

The patient was placed in supine position with the head slightly turned the opposite side then disinfection of the skin was done by povidone iodine $10 \%$ solution \& draped. Equipment used in technique were sterile towels, gauze packs, $20 \mathrm{ml}$ syringes filled with local anesthetic solution and 25 -gauge needle and $2 \mathrm{ml}$ lidocaine $2 \%$. Needle type was 20 -gauge, $50 \mathrm{~mm}$ length needle for infiltration of local anesthetics (visioplex $®$-vygonfrance). Ultrasound machine was phillipis ex50 extreme edition and a $12 \mathrm{MHz}$ linear type probe.

Asterile cover was used over the transducer along with a sterile gel.

The probe is positioned in the transverse plane at the level of sixth cervical vertebra deep to the sternocleidomastoid muscle to identify the carotid artery. Once the artery is identified, the transducer is moved slightly laterally across the neck till the nerve roots of the brachial plexus visualized as round hypoechoic structures in the groove between the anterior and middle scalene muscles, where they are present within their own fascial sheath.

Using a 25 -gauge needle, 1 to $2 \mathrm{~mL}$ of lidocaine $2 \%$ was injected into the skin $1 \mathrm{~cm}$ lateral to the probe to decrease the discomfort during needle insertion. The needle is inserted in-plane toward the brachial plexus in a lateral to medial direction Here the roots of the plexus appear as three vertically aligned, hypoechoic structures and referred to as the traffic light sign. Careful aspiration was done to exclude an intravascular needle placement $\&$ then 1 to $2 \mathrm{~mL}$ of local anesthetic was injected to document the proper needle placement. After confirmation of proper injection, the total volume of local anesthetic was injected \& seen displacing the brachial plexus away from the needle.

All of the interscalene nerve blocks was performed by a single anesthesiologist who was blinded to group allocation. The study data were recorded by an anesthesia resident who was blinded to the patient groups. Sensory block was assessed by pinprick test using a three-point scale in the $\mathrm{C} 5$, C6, C7 \& C8 sensory dermatome distribution and compared with the contralateral arm as a reference where $[0=$ normal sensation; $1=$ loss of sensation of pinprick (analgesia); and 2=loss of sensation of touch (anesthesia)]. Shoulder abduction was used to assess motor function where: [ $0=$ normal abduction, $1=$ decreased movement, moved shoulder but not normal, $2=$ unable to abduct the shoulders]. 
Successful block was achieved when sensory block grade 2 (loss of sensation of touch) \& motor block at 2 scale (unable to abduct the shoulders) have been reached. Patients in whom block success couldn't be achieved after 30min, GA was given, and the patients were excluded from data analysis.

After confirmation of successful sensory block, GA was induced with fentanyl $1 \quad \mathbf{k g}$ propofol $2 \mathrm{mg} / \mathrm{kg}$ and cisatracurium $0.15 \mathrm{mg} / \mathrm{kg}$ to facilitate endotracheal intubation. Anesthesia was maintained with isoflurane $1-2 \%$ in oxygen, maintenance dose of cisatracurium $0.03 \mathrm{mg} / \mathrm{kg}$ on need \& maintenance fluids were given.

Hypotension was defined to be a fall in MAP $>20 \%$ from baseline and treated with bolus of $100 \mathrm{ml}$ fluid and if uncorrected, IV ephedrine $6 \mathrm{mg}$ bolus. Bradycardia was defined as HR $\leq 50 / \mathrm{min}$ and treated with Atropine $0.6 \mathrm{mg}$ IV bolus.

At the end of surgery, neostigmine $2.5 \mathrm{mg}$ and atropine $1 \mathrm{mg}$ were used to reverse residual neuromuscular blockade. Patients were extubated and transferred to Post Anesthesia Care Unit (PACU).

The following data were measured for each patient: Age, sex, ASA physical status, duration of operation, type of surgery. Hemodynamic status (HR, MAP) which were recorded before performing the block (base line T0), then at skin incision (T1) at 30 (T2), 60 (T3), 90 (T4) \& 120 minutes after skin incision (T5) and at $2 \mathrm{~h}, 4 \mathrm{~h}, 6 \mathrm{~h} \& 8 \mathrm{~h}$ postoperatively.

Onset of sensory block (the time from the end of injection till the loss of sensation grade 2 in all dermatomal distributions of C5 \& C6), onset of motor block [it is the time taken from end of injection until onset of complete loss of the motor power (Grade 2)], duration of sensory block (time taken from injection of the drug till first experience of pain), duration of motor block [the time from the end of the injection till the return of motor power (Grade 0)].

Post-operative pain was measured using VAS: On arrival to PACU, then at 2, 4, 6, $8 \& 12 \mathrm{hr}$ after the end of surgery (Meperidine $10 \mathrm{mg}$ was administered intravenously as a rescue analgesic when the VAS $\geq 4$ \& repeated till VAS became less than 3 or up to a total dose of meperidine $100 \mathrm{mg}$ ). Total dose of rescue analgesic consumed over $12 \mathrm{hrs}$ post-operatively $\&$ number of patients received rescue analgesics were recorded. Sedation will be assessed using sedation score at 2, 4, 6, 8 \& $12 \mathrm{hrs}$ post-operatively as follow: [Grade 1: Awake and alert, Grade 2: Responding to verbal stimulus, Grade 3: Responding to mild physical stimulus and Grade 4: Responding to moderate-or-severe physical stimulus].

Onset of ${ }^{1 \text { st }}$ dose of rescue analgesia (time interval between the end of local anesthetic administration and the first request of a rescue analgesic), total dose of meperidine consumption and incidence of complications (such as hypotension, bradycardia, nausea, vomiting, were recorded \& managed. All complications related to interscalene block as hemidiaphragmatic paralysis, Horner's syndrome, pneumothorax, hematoma or intravascular injection).

\section{Statistical analysis:}

Our primary outcome was the duration of sensory block. Based on the results of a previous study [5], a sample size was calculated to be 11 patients in each group needed to detect a significant difference in the duration of sensory block of 60 minutes with a standard deviation of 40.5 at $\alpha$ error of 0.05 and power of study of $90 \%$. We enrolled 15 cases per group to overcome possible dropouts.

The statistical software SPSS 16 (SPSS Inc., Chicago, IL, USA) was utilized for statistical analysis. Normality of data was checked with the Shapiro-Wilk test. The parametric data were expressed as mean \pm SD and was analyzed utilizing student $t$-test. VAS score was analyzed among the studied groups utilizing the Mann-Whitney test. Categorical data were presented as patients' number or frequencies (\%) and were analyzed utilizing the Chi-square test or Fisher's exact test when appropriate. $p$-value $<0.05$ was considered significant.

\section{Results}

In this study, 53 patients were assessed for eligibility, 5 patients did not meet the inclusion criteria and 3 patients their guardians refused to participate in the study. 45 patients were randomly allocated into three equal groups (15 patients in each one); Group I: Bupivacaine group (Control group), Group II: Magnesium sulphate group ( $\mathrm{Mg}$ group), Group III: Dexmedetomidine group (Dex group). Fig. (1).

There was no significant difference as regard to age, sex, ASA physical status and duration of surgery (Table 1). Type of surgery was rotator cuff repair $(26.7 \%)$, subacromial impingement $S$. $(17.8 \%)$, recurrent shoulder dislocation (28.9\%) and slap lesion $(22.2 \%)$. 
Our results showed significant decrease in HR, MAP, the onset of sensory block, VAS and the total dose of rescue analgesic and significant prolongation in the duration of sensory block and the onset of 1 st analgesic requirements in $\mathrm{Mg}$ group \& Dex group when compared to control group \& also Dex group was superior to $\mathrm{Mg}$ group (Table 2), Figs. (2-4).

As regard sedation score and adverse effects, there was no significant difference (Table 3), Fig. (5).

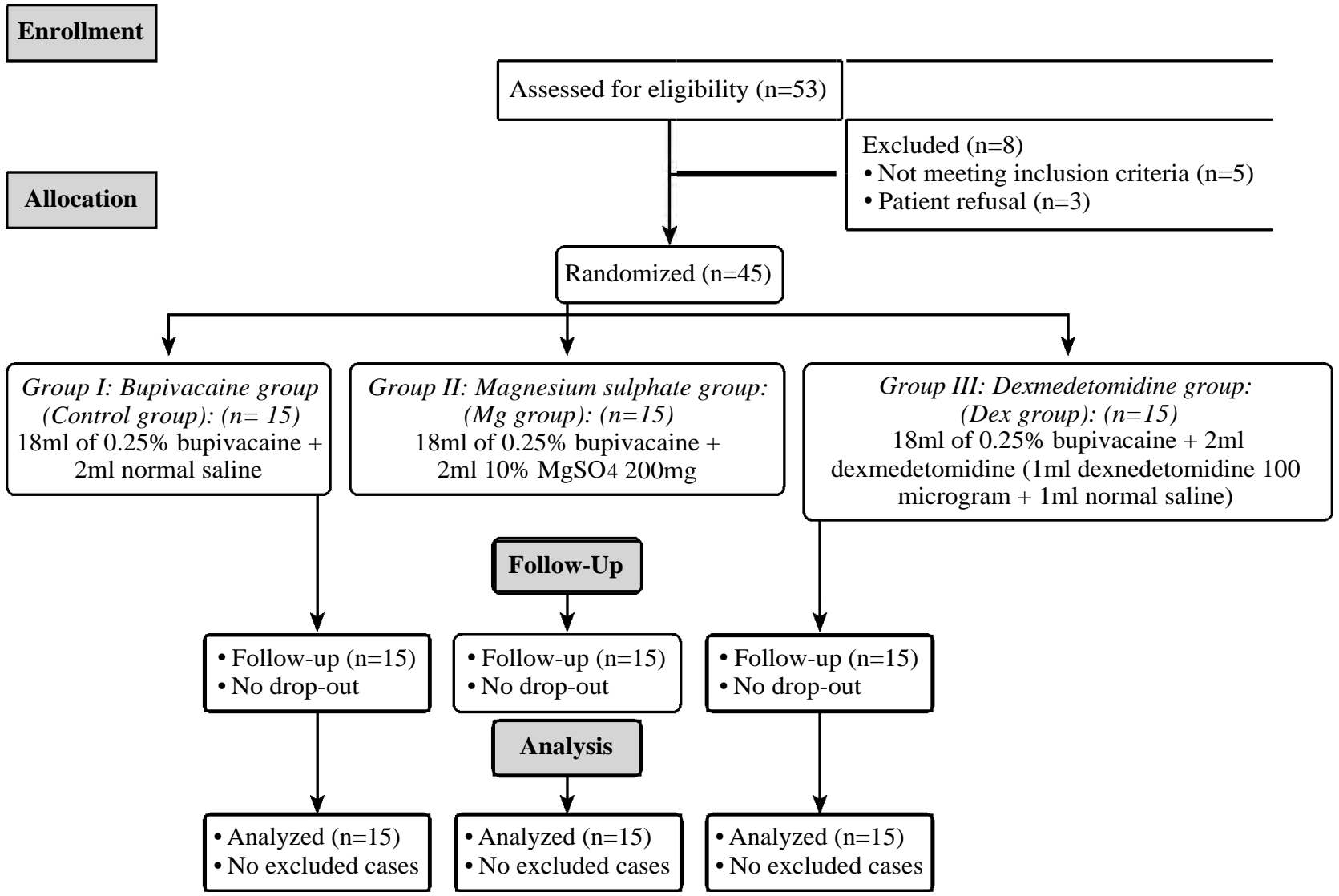

Fig. (1): Patient flowchart summarizing enrollment, allocation, follow-up and analysis in the study protocol.
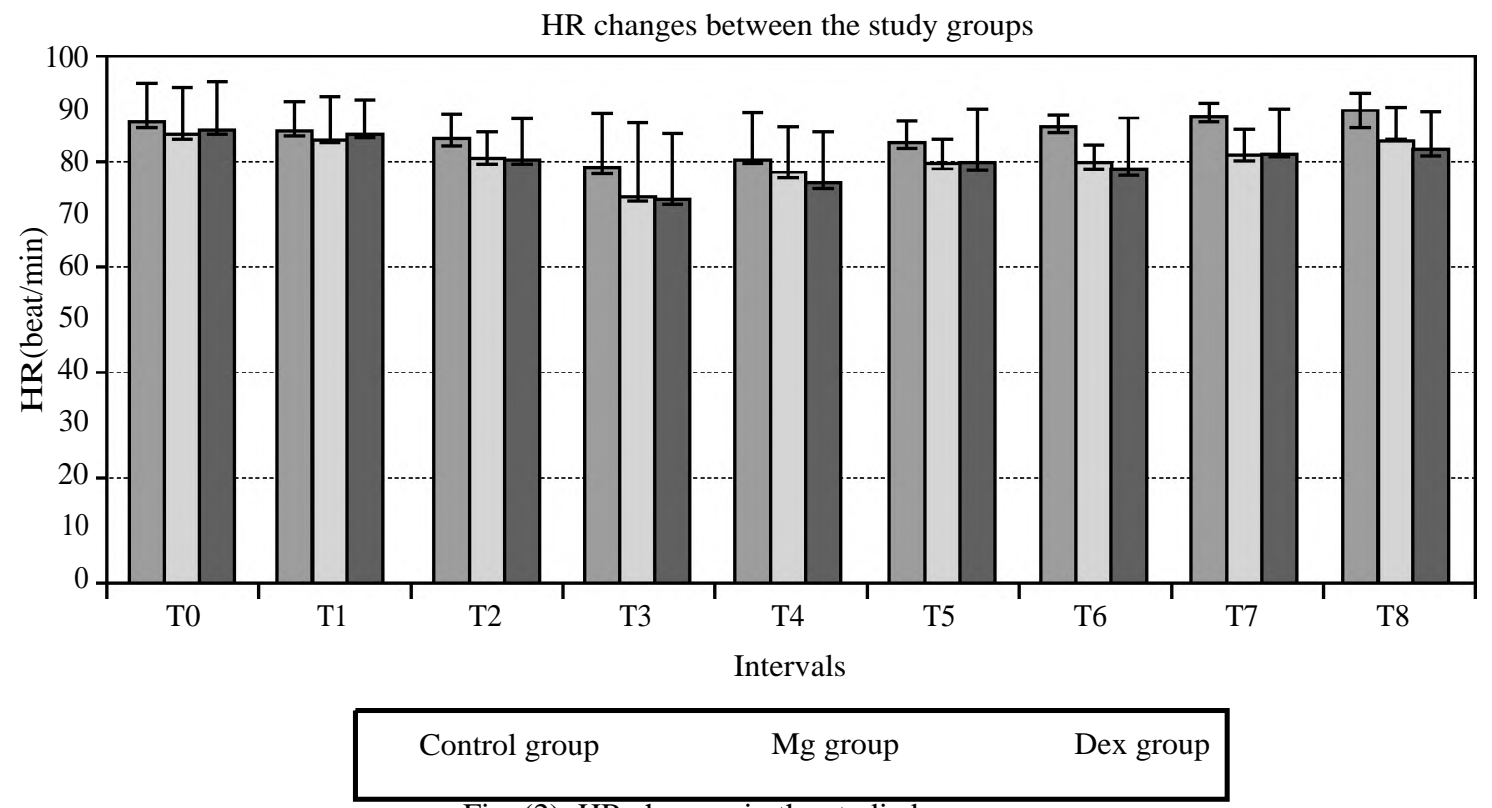

Fig. (2): HR changes in the studied groups. 


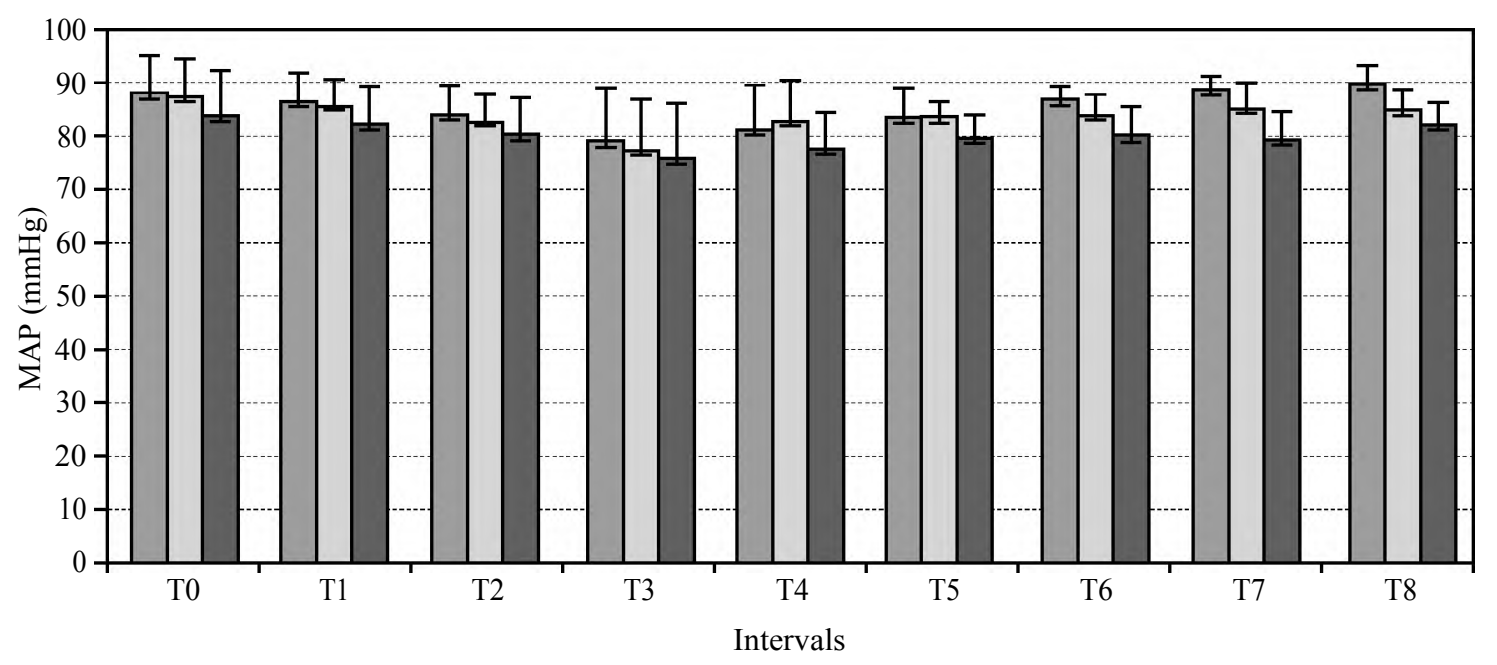

\begin{tabular}{|lll|}
\hline Control group & Mg group & Dex group \\
\hline
\end{tabular}

Fig. (3): MAP changes in the studied groups.



Fig. (4): VAS changes in the studied groups.



Fig. (5): Sedation score in the three studied groups.

Table (1): Demographic data and diagnosis in the three groups.

\begin{tabular}{llcccc}
\hline & $\begin{array}{c}\text { Control group } \\
(\mathrm{n}=15)\end{array}$ & $\begin{array}{c}\mathrm{Mg} \text { group } \\
(\mathrm{n}=15)\end{array}$ & $\begin{array}{c}\text { Dex group } \\
(\mathrm{n}=15)\end{array}$ & $\begin{array}{c}\text { Test of } \\
\text { sig. }\end{array}$ & $\begin{array}{c}p \text { - } \\
\text { value }\end{array}$ \\
\hline $\begin{array}{l}\text { Age }(y): \\
\quad \text { Mean } \pm \mathrm{SD}\end{array}$ & $43.4 \pm 15.99$ & $39.6 \pm 17.3$ & $40.2 \pm 12.5$ & $\mathrm{~F}=0.264$ & 0.769 \\
Sex (M/F) & $7 / 8$ & $8 / 7$ & $9 / 6$ & $\chi^{2}=0.536$ & 0.765 \\
ASA (I/II) & $9 / 6$ & $7 / 8$ & $8 / 7$ & $\chi^{2}=0.903$ & 0.637 \\
$\begin{array}{l}\text { Duration of surgery (min) }): \\
\quad\end{array}$ & $137.87 \pm 9.56$ & $134.6 \pm 10.93$ & $136.53 \pm 9.72$ & $\mathrm{~F}=0.371$ & 0.692 \\
\hline
\end{tabular}


Table (2): Onset of sensory block (min), duration of sensory block (hr), 1 st dose of analgesic requirements (hr) and doses of rescue analgesia (mepridine $(\mathrm{mg})$ ).

\begin{tabular}{|c|c|c|c|c|c|c|}
\hline & $\begin{array}{l}\text { Control group } \\
(\mathrm{n}=15)\end{array}$ & $\underset{(\mathrm{n}=15)}{\operatorname{Mg} \text { group }}$ & $\begin{array}{l}\text { Dex group } \\
(\mathrm{n}=15)\end{array}$ & $\begin{array}{l}\text { Test of } \\
\text { sig. }\end{array}$ & $\begin{array}{c}p- \\
\text { value }\end{array}$ & \\
\hline \multicolumn{7}{|l|}{ Onset of sensory block (min): } \\
\hline Mean \pm SD & $15.57 \pm 2.37$ & $12.27 \pm 2.01$ & $9.1 \pm 1.31$ & $\mathrm{~F}=41.4$ & $<0.001 *$ & $\begin{array}{l}p_{1}<0.001 * \\
p_{2}<0.001 *\end{array}$ \\
\hline \multirow{2}{*}{$\begin{array}{l}\text { Duration of sensory block }(h r) \text { : } \\
\quad \text { Mean } \pm \text { SD }\end{array}$} & & & & & & $p_{3}<0.001 *$ \\
\hline & $5.2 \pm 0.56$ & $7.93 \pm 0.8$ & $11.93 \pm 1.22$ & $\mathrm{~F}=210.8$ & $<0.001 *$ & $\begin{array}{l}p_{1}<0.001 * \\
p_{2}<0.001 * \\
p_{2}<0.001 *\end{array}$ \\
\hline \multirow{2}{*}{$\begin{array}{l}\text { 1st dose of analgesic requirements }(h r) \text { : } \\
\quad \text { Mean } \pm \mathrm{SD}\end{array}$} & & & & & & $p_{3}<0.001 *$ \\
\hline & $3 \pm 0.76$ & $5.53 \pm 0.99$ & $9.53 \pm 1.46$ & $\mathrm{~F}=20.8$ & $<0.001 *$ & $\begin{array}{l}p_{1}<0.001^{*} \\
p_{2}<0.001^{*}\end{array}$ \\
\hline \multirow{2}{*}{$\begin{array}{l}\text { Doses of rescue analgesia (mepridine }(m g)) \text { : } \\
\quad \text { Mean } \pm \mathrm{SD}\end{array}$} & & & & & & $p_{3}<0.001 *$ \\
\hline & $61.33 \pm 11.26$ & $42.67 \pm 7.04$ & $22.67 \pm 5.94$ & $\mathrm{~F}=79.6$ & $<0.001 *$ & $\begin{array}{l}p_{1}<0.001 * \\
p_{2}<0.001 * \\
p_{3}<0.001 *\end{array}$ \\
\hline
\end{tabular}

Table (3): Adverse effects in the three groups.

\begin{tabular}{|c|c|c|c|c|c|c|c|}
\hline \multirow[b]{3}{*}{ Hypotension } & \multicolumn{2}{|c|}{ Control group } & \multicolumn{2}{|c|}{ Mg group } & \multirow{2}{*}{\multicolumn{2}{|c|}{$\frac{\text { Dex group }}{\text { Number } \%}$}} & \multirow{3}{*}{$\begin{array}{c}\begin{array}{c}p- \\
\text { value }\end{array} \\
0.593\end{array}$} \\
\hline & \multirow{2}{*}{$\frac{\text { Number }}{2}$} & \multirow{2}{*}{$\frac{\%}{13.33}$} & \multirow{2}{*}{$\frac{\text { Number }}{3}$} & \multirow{2}{*}{$\frac{\%}{20}$} & & & \\
\hline & & & & & 3 & 20 & \\
\hline Bradycardia & 2 & 13.33 & 3 & 20 & 3 & 20 & 0.593 \\
\hline Nausea \& vomiting & 2 & 13 & 1 & 6 & 1 & 6 & 0.76 \\
\hline Phrenic palsy & 3 & 20 & 4 & 26.60 & 3 & 20 & 0.879 \\
\hline
\end{tabular}

\section{Discussion}

Interscalene block is a widely used technique for post-operative analgesia in shoulder surgery. However, duration of analgesia is limited to the type of local anesthetic used, so combinations with adjuvants such as $\alpha_{2}$ agonists, corticosteroids, neostigmine \& $\mathrm{MgSO} 4$ which prolong postoperative analgesic effect [6].

In our study, HR \& MAP showed significant decrease at 4, 6, 8hr post-operatively in $\mathrm{Mg} \& \mathrm{Dex}$ groups as compared to control with more decrease in Dex group than in Mg group. We attributed this to the post-operative pain control, also decrease in the sympathetic stimulation \& stress response to surgery. $\mathrm{MgSO} 4$ prevents the adrenal medullary and adrenergic nerve endings release of catecholamines, has a direct effect on blood vessels producing vasodilatation and attenuates vasopressinmediated vasoconstriction [7,8]. Dexmedetomidine inhibits the release of norepinephrine by presynaptic $\alpha_{2}$ receptor activation and inhibits sympathetic stimulation by postsynaptic activation; decreasing HR and MAP [9].

Our results are in agreement with Agarwal S et al., [10] who showed that there was a significant decrease in MAP \& HR in DEX group when com- pared to control group in supraclavicular block. Also, Manohar P [11] showed that MAP \& HR were significantly reduced in patients received dexmedetomidine \& bupivacaine when compared to bupivacaine group in supraclavicular block. Patients were scheduled for upper limb surgeries involving the distal arm \& forearm and assigned to three equal groups (30 patients each with volume of 30ml): Group B: Bupivacaine 0.5\%, Group BF: Bupivacaine $0.5 \%$ with $50 \mathrm{mcg}$ fentanyl and Group BD: Bupivacaine $0.5 \%$ with $50 \mathrm{mcg}$ dexmedetomidine.

In contrast to our study, Harshavardhana HS [12] showed that there was no a statistically significant difference between control group \& DEX group as regard MAP \& HR with supraclavicular block. Delgado V et al., [6] concluded that there was no significant difference between control group \& DEX group with interscalene block. In the previous two studies the results may be due to the difference in the dose of dexmedetomidine which was $1 \mathrm{~g} / \mathrm{kg}$ while in our study we gave $100 \mathrm{~g}$ fo all patients.

Also Lee AR et al., [13], who studied patients scheduled for rotator cuff repair under interscalene block using nerve stimulator technique \& US guidance and patients were randomly allocated into 
two groups: One group received bupivacaine $0.5 \%$ with adrenaline and the other group received bupivacaine $0.5 \%$ with adrenaline plus $10 \% \mathrm{MgSO}_{4}$ $2 \mathrm{ml}$ and they concluded that there was no a statistically significant difference in hemodynamics between the two groups. In addition, Abdelfatah AM et al., [5] studied the effect of adding $\mathrm{MgSO}_{4}$ to lidocaine in an interscalene block for shoulder arthroscopic acromioplasty and found no significant difference than lidocaine. They used 500mg MgSO 4 while we used $200 \mathrm{mg}$.

Our results showed that dexmedetomidine \& $\mathrm{MgSO} 4$ when added to bupivacaine in interscalene block has led to enhancement of the onset \& prolongation of the duration of the sensory block as compared control group. We explained our results by the effect of $\mathrm{MgSO} 4 \&$ dexmedetomidine in pain control as follows: $\mathrm{Mg}+{ }^{2}$ blocks NMDA receptors (prevent central sensitization caused by peripheral nociceptive stimulation) and has antinociceptive action based on the regulation of calcium influx. Dexmedetomidine inhibits descending noradrenergic pathway (which modulates neurotransmission of nociception), resulting in analgesia.

Our results are consistent with Manohar P et al., [11] concluded that the onset of sensory blocks was quicker \& the duration of analgesia was prolonged in dexmedetomidine group compared to bupivacaine group. In addition, Agarwal S et al., [10] concluded that the onset of sensory block was significantly fasten \& the duration of sensory block was prolonged in dexmedetomidine group as compared to control group. Also, Fritsch G et al., [14] showed that the addition of dexmedetomidine $150 \mu \mathrm{g}$ to $12 \mathrm{~mL}$ ropivacaine $0.5 \%$ in interscalene block led to enhancement of the onset \& prolongation of the duration of sensory block.

In contrast to our study Lee AR et al., [13] who showed that there was no significant difference between the two groups as regard the onset of sensory \& motor block and the duration of sensory block, but the duration of analgesia was significantly prolonged in magnesium group as compared to bupivacaine group. Also, Kumar AN [15] studied three groups Group bupivacaine, Group D bupivacaine with $8 \mathrm{mg}$ dexamethasone and Group DEX bupivacaine with 50ùg dexmedetomidine and demonstrated that there was no significant difference between the studied groups as regard to the onset of sensory block, but the duration of sensory block was significantly prolonged in DEX group as compared to group C. We attributed this difference to the dose of dexmedetomidine which was 50ùg while in our study it was 100 ùg.
As regard VAS, there was significant decrease at $4,6,8,12 \& 15$ h post-operatively in $\mathrm{Mg} \&$ Dex groups as compared to control group with significant decrease in Dex group at $12 \mathrm{~h} \& 15 \mathrm{~h}$ postoperatively as compared to $\mathrm{Mg}$ group. As regard onset of first dose of rescue analgesics, it was delayed $\&$ the total dose of rescue analgesics was decreased in Dex group as compared to control \& $\mathrm{Mg}$ groups and in $\mathrm{Mg}$ group as compared to control group. But, there was no significant difference in sedation score between the three studied groups.

In agreement with our study Bengisun ZK et al., [1]. Patients underwent interscalene plexus block for arthroscopic shoulder surgery and randomized into 2 groups: Group L received levobupivacaine and epinephrine; and Group LD, received levobupivacaine, epinephrine and dexmedetomidine. The study showed that VAS was lower \& the total dose of post-operative analgesic requirements was significantly reduced in LD group at all times as compared to group L.

Also, Gurajala I et al., [16] studied supraclavicular block and concluded that VAS was lower, the duration of analgesia was prolonged, but in contrast to our results, they found that sedation score was lower in RD group (ropivacaine $0.5 \%+50 \mu \mathrm{g}$ dexmedetomidine) than $\mathrm{R}$ group (ropivacaine $0.5 \%$ alone).

In addition, Lee AR et al., [13] who showed that VAS was lower and prolonged analgesia in Magnesium group than in Bupivacaine group. However, post-operative analgesic requirements and sedation score was the same in both groups.

Also, Abdelfatah AM et al., [5] demonstrated that the numeric rating scale $\&$ post-operative analgesic requirements was significantly decreased in (Lidocaine-Magnesium) group as compared to lidocaine group but there was no significant difference in sedation score.

As regard the adverse effects: There was no significant difference between the studied groups (Dex group \& Mg group showed a slight higher incidence of hypotension \& bradycardia than in control group). PONV had lower incidence in Dex group \& Mg group than in control group but without any significance. We explained that difference to the post-operative analgesia which was prolonged $\&$ more efficient in Dex \& Mg groups than in control group \& this led to less opioid needed, so post-operative opioid related nausea $\&$ vomiting was lower. 
Manohar P et al., [11] found that bradycardia event was higher in patients received dexmedetomidine than bupivacaine alone but, the incidence of hypotension and PONV was comparable. Kumar $\mathrm{N}$ [17] showed that PONV rate was lower in Dex group than in bupivacaine group.

\section{Conclusion:}

Dexmedetomidine $100 \mu \mathrm{g}$ was better than magnesium sulphate $200 \mathrm{mg}$ when they added to bupivacaine $0.25 \%$ in US guided interscalene brachial plexus block as evidenced by prolongation of the duration of sensory block, improved quality of post-operative analgesia, decreased requirements of rescue analgesics and providing desirable sedation without side effects.

\section{Conflicts of interest: Nil.} role.

Authors' contributions: All authors had equal

\section{References}

1- BENGISUN Z.K., EKMEKCI P., AKAN B., KÖROGLU A. and TÜZÜNER F.: The effect of adding dexmedetomidine to levobupivacaine for interscalene block for postoperative pain management after arthroscopic shoulder surgery. Clin. J. Pain, 30 (12): 1057-61, 2014.

2- BUVANENDRAN A. and KROIN J.S.: Multimodal analgesia for controlling acute post-operative pain. Curr. Opin. Anaesthesiol., 22 (5): 588-93, 2009.

3- LAIQ N., KHAN M.N., ARIF M. and KHAN S.: Midazolam with bupivacaine for improving analgesia quality in brachial plexus block for upper limb surgeries. J. Coll Physicians Surg. Pak., 18 (11): 674-8, 2008.

4- LASHGARINIA M., NAGHIBI K., HONARMAND A., SAFAVI M. and KHAZAEI M.: Effect of ketamine as an adjuvant in ultrasound-guided supraclavicular brachial plexus block: A double-blind randomized clinical trial study. Adv. Biomed. Res., 3: 232-40, 2014.

5- ABDELFATAH A.M. and ELSHAER A.N.: The effect of adding magnesium sulfate to lidocaine in an interscalene plexus block for shoulder arthroscopic acromioplasty. Ain-Shams J. Anaesthesiol., 7 (1): 59-64, 2014.

6- VELÁZQUEZ-DELGADO E., GASPAR-CARRILLO S., PEÑA-RIVERON A. and MEJÍA-TERRAZAS G.: Postoperative analgesia with dexmedetomidine in interscalene block. Comparative study. Rev. Esp. Anestesiol. Reanim., 64 (3): 137-43, 2017.
7- DAR S., GUPTA D., DEOPUJARI R. and GOMES P.: Effect of Magnesium Sulphate on Attenuation of Hemodynamic Stress Responses during Laparoscopic Abdominal Surgeries. J. Anesth. Clin. Res., 6 (590): 2, 2015.

8- JEE D., LEE D., YUN S. and LEE C.: Magnesium sulphate attenuates arterial pressure increase during laparoscopic cholecystectomy. Br. J. Anaesth., 103 (4): 484-9, 2009.

9- MANOHAR P. and PRAKASH M.: Comparison of the effects of fentanyl and dexmedetomidine in supraclavicular brachial plexus block achieved with $0.5 \%$ bupivacaine in Karpaga Vinayaga Medical College and Hospital, Maduranthagam. JMSCR, 3 (8): 7131-8, 2015.

10-AGARWAL S., AGGARWAL R. and GUPTA P.: Dexmedetomidine prolongs the effect of bupivacaine in supraclavicular brachial plexus block. J. Anaesthesiol. Clin. Pharmacol., 30 (1): 36, 2014.

11- MANOHAR P. and PRAKASH M.: Comparison of the effects of fentanyl and dexmedetomidine in supraclavicular brachial plexus block achieved with $0.5 \%$ bupivacaine in Karpaga Vinayaga Medical College and Hospital, Maduranthagam. JMSCR, 3: 7131-8, 2015.

12-HARSHAVARDHANA H.: Efficacy of dexmedetomidine compared to clonidine added to ropivacaine in supraclavicular nerve blocks: A prospective, randomized, double blind study. IJMHS, 3 (2): 127-32, 2014.

13- LEE A.R., YI H.W., CHUNG I.S., KO J.S., AHN H.J., GWAK M.S., et al.: Magnesium added to bupivacaine prolongs the duration of analgesia after interscalene nerve block. Can. J. Anaesth., 59 (1): 21-7, 2012.

14- FRITSCH G., DANNINGER T., ALLERBERGER K., TSODIKOV A., FELDER T.K., KAPELLER M., et al.: Dexmedetomidine added to ropivacaine extends the duration of interscalene brachial plexus blocks for elective shoulder surgery when compared with ropivacaine alone: A single-center, prospective, triple-blind, randomized controlled trial. Reg. Anesth. Pain Med., 39 (1): 37-47, 2014.

15- KUMAR A.N.: Comparative study between $0.25 \%$ bupivacaine with $8 \mathrm{mg}$ dexamethasone and $0.25 \%$ bupivacaine with $50 \mu \mathrm{g}$ dexmedetomidine as adjuvant for interscalene brachial plexus block: Prospective clinical study. J. Evol. Med. Dent. Sci., 3 (58): 13111-9, 2014.

16- GURAJALA I., THIPPARAMPALL A.K., DURGA P. and GOPINATH R.: Effect of perineural dexmedetomidine on the quality of supraclavicular brachial plexus block with $0.5 \%$ ropivacaine and its interaction with general anaesthesia. Indian J. Anaesth., 59 (2): 89-95, 2015.

17- KUMAR A.N.: Comparative study between $0.25 \%$ bupivacaine with $8 \mathrm{mg}$ dexamethasone and $0.25 \%$ bupivacaine with $50 \mu \mathrm{g}$ dexmedetomidine as adjuvant for interscalene brachial plexus block: Prospective clinical study. Clinical study, 3 (58): 3, 2014. 


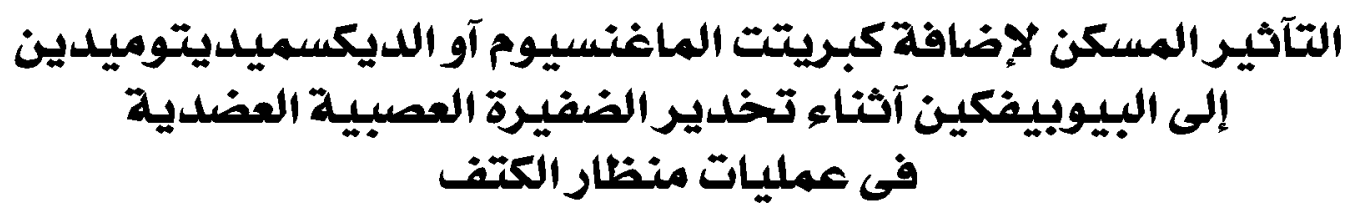

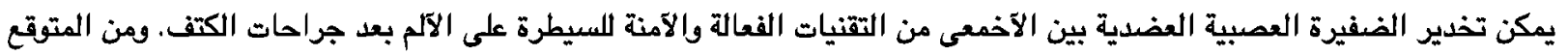
آن إضافة كبريتات الماغنسيوم آو الديكسميديتوميدين إلى البيوبيفكين يزيد من مدة التخدير بدون آثار جانبية غير مرغوبة.

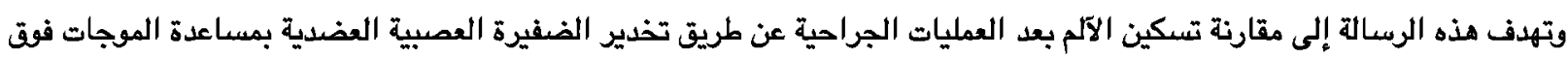


بعد حساب حجم العينة فإن إجمالى عدد المرضى كان 20 مريضاً تثم تقسيمهم إلى ب مجموعات كل مجموعة 10 مريضاً:

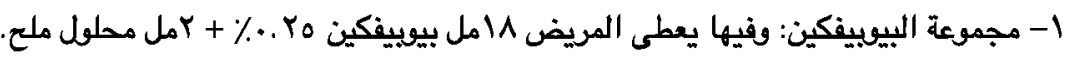

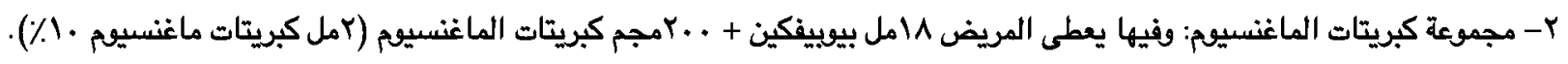



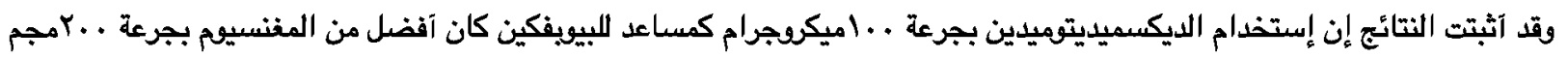



